\title{
Transvaginal Hydrolaparoscopy by Flexible Fiberscope - A Study of Preliminary Cases -
}

\author{
AKIO KATAOKA, SHOUKO HIRAKAWA, MANAMI IWAMOTO, YUMI SAKUMURA \\ AND RYOUTA YOSHINAGA
}

Clinic of Obstetrics and Gynecology, Kataoka Ladies Clinic, Yatsushiro 866-0861, Japan

Received 5 September 2011, accepted 11 January 2012

\author{
Edited by DAIZO HORI
}

\begin{abstract}
Summary: Transvaginal hydrolaparoscopy (THL) has become a first-line procedure in infertile women, and THL by flexible fiberscope (THLF) is a less traumatic and a more suitable outpatient procedure than diagnostic laparoscopy. We performed THLF on infertile women based on four indications; (i) tubal obstruction and/or peritubal adhesion as suggested by hysterosalpingography (HSG); (ii) serum antibody against Chlamydia $(C)$ positive for trachomatis; (iii) diagnosis of early stage endometriosis; and (iv) unexplained infertility. Seven women with a chief complaint of infertility were the subjects of the present study. Two of the 7 cases had a history of gynecological surgery. Six of 7 cases had a history of $C$. trachomatis infection. Four cases had abnormal findings of fallopian tubal patency in hysterosalpingography. Parafallopean tubal atresia and tubal obstruction were observed in 4 cases by THLF. In one case the bilateral ovaries were extremely small and atrophic. None of the cases had serious complications after THLF. After the THLF, six women were able to have a baby by assisted reproductive technology (ART) within two years.

As THL was developed using a solid scope, indications for THL have been limited, and have excluded cases with retroverted uterus or peritoneal surgical history. In the present study, THL using a fiberscope was carried out in infertile women with retroverted uterus, and in women with a history of peritoneal cavity surgery to examine the feasibility of extending the indications for THL. Findings on the THLF were given precedence in deciding further treatment strategies. We believe that THLF can be useful in helping patients with these indications to successfully achieve early pregnancy. This study is the first trial of THLF.
\end{abstract}

Key words transvaginal hydrolaparoscopy, tubal infertility, endometriosis, assisted reproductive technology, laparoscopy

\section{INTRODUCTION}

Since transvaginal hydrolaparoscopy (THL) was introduced as a first-line procedure for early stage exploration of the adnexal structures in infertile women, it has been shown that THL is a less traumatic and a more suitable outpatient procedure than diagnostic laparoscopy [1-3]. Transvaginal access and the systemic use of hydro flotation are potential advantages of THL for the exploration of tubo-ovarian structures in infertility [1-6]. Moreover, inspection under fluid in THL improves the visualization of distal tubal disease [1-8]. The risks of a general anesthetic are avoided, and there is less chance of trauma to major vessels $[8,9]$. THL was developed for use with a solid scope, so the indications for THL have been limited, excluding cases with retroverted uterus or peritoneal surgical history. We have been performing THL by flexible fiberscope (THLF) as a diagnostic laparoscopy on infertile women based on any of the following four

Address for correspondence: Akio Kataoka, 3-3-35 Honmachi, Yatsushiro-shi, Kumamoto, 866-0861, Japan. Tel: 81-965-32-2344 Fax:81-965-31-1367

Abbreviations: ART, assisted reproductive technology; THL, transvaginal hydrolaparoscopy; THLF, transvaginal hydrolaparoscopy by flexible fiberscope; HSG, hysterosalpingography. 
indications; (i) tubal obstruction and/or peritubal adhesion as suggested by hysterosalpingography (HSG); (ii) serum antibody against Chlamydia $(C)$ positive for trachomatis; (iii) diagnosis of early stage endometriosis; and (iv) unexplained infertility.

The present study of THLF in infertile women included three patients with retroverted uterus and history of peritoneal cavity surgery to examine the feasibility of extending the indications for THL to include these characteristics. THLF findings were given precedence in deciding further treatment strategies. We believe that THLF is useful helping such patients to successfully achieve early pregnancy. This study is the first study of THLF.

\section{MATERIALS AND METHODS}

The THL procedure followed that of Gordts et al. [1-3]. Women with a retroverted uterus have been excluded from THL because Darai et al. [4,7] suggested it should be considered as a relative contra-indication for THL. Briefly, THLF was performed under spinal anesthesia in the lithotomy position. After disinfection, a Hy-cath (Sumitomo Bakelite Co. Ltd, Tokyo, Japan) was inserted into the uterine cavity for the use of chromotubation. The uterine cervix was lifted by means of a tenaculum placed on the posterior lip.

Tubo-ovarian structures and tubal passage were investigated using a flexible fiberscope (Mochida Co, Tokyo, Japan). Approximately $500 \mathrm{ml}$ of saline was instilled into the pouch of Douglas through a Hy-cath.
A 5.5-mm fiberscope was inserted by a stab incision in the posterior fornix, then the fiberscope was used with a flow channel attached to a 3 CCD digital video camera. The saline irrigation was continued throughout the procedure to keep the bowel and tubo-ovarian structures afloat. The posterior of the uterus and the tuboovarian structures were carefully observed, and tubal passage was confirmed using indigocarmin.

\section{PATIENTS AND RESULTS}

We have been performing diagnostic laparoscopy using THLF on infertile women based on any of the following four indications; (i) tubal obstruction and/or peritubal adhesion suggested by the HSG; (ii) positive serum antibody against C. trachomatis ; (iii) diagnosis of early stage endometriosis; and (iv) unexplained infertility. Case reports are presented in Table 1. Seven women with a chief complaint of infertility were entered in this pilot study after informed consent. Two of 7 cases had a history of gynecological surgery. Six out of 7 cases had a history of $C$. trachomatis infection as diagnosed by serum antibody titres (IgG and $\operatorname{IgA}$ ) against $C$. trachomatis. Four cases had abnormal findings of fallopian tubal patency in hysterosalpingography. Parafallopean tubal atresia and tubal obstruction were observed in 4 cases by THLF (Figs 1, 2, 3 and 4). In one case the bilateral ovaries were extremely small and atrophic. None of the cases had serious complications after THLF, and all were discharged the day after the procedure. After the THLF, six women were able

TABLE 1 .

Pients and results

\begin{tabular}{|c|c|c|c|c|c|c|c|}
\hline & Case 1 & Case 2 & Case 3 & Case 4 & Case 5 & Case 6 & Case 7 \\
\hline Age & 37 & 28 & 29 & 32 & 34 & 36 & 30 \\
\hline $\begin{array}{l}\mathrm{PH} / \text { Uterine } \\
\text { findings }\end{array}$ & $\begin{array}{c}\text { Ectopic } \\
\text { pregnancy }\end{array}$ & & $\begin{array}{l}\text { Retroverted } \\
\text { uterus }\end{array}$ & & & $\begin{array}{l}\text { Ovarian } \\
\text { cystectomy }\end{array}$ & \\
\hline Infertility term & 4yr6mo & 4yr10mo & $3 y r 10 \mathrm{mo}$ & $3 y r 2 \mathrm{mo}$ & $2 \mathrm{yr} 6 \mathrm{mo}$ & 4yr1mo & $5 \mathrm{yr} 1 \mathrm{mo}$ \\
\hline $\begin{array}{l}\text { Chamydia IgG/ } \\
\text { IgA }\end{array}$ & $+/+$ & $+1-$ & $+1-$ & $+/+$ & $+/+$ & $-1-$ & $+1-$ \\
\hline HSG & BTO & N.F. & BTO & BTO & PFA & N.F. & N.F. \\
\hline THLF & $\begin{array}{c}\text { PFA by } \\
\text { Chlamydia } \\
\text { and endome- } \\
\text { triosis }\end{array}$ & $\begin{array}{l}\text { Abnormal } \\
\text { tubal open }\end{array}$ & $\begin{array}{c}\text { BTO by } \\
\text { endometriosis }\end{array}$ & $\begin{array}{l}\text { BTO by } \\
\text { Chlamydia }\end{array}$ & N.F. & $\begin{array}{l}\text { Atrophic } \\
\text { ovary }\end{array}$ & $\begin{array}{c}\text { PFA by } \\
\text { Chlamydia } \\
\text { and endome- } \\
\text { triosis }\end{array}$ \\
\hline $\begin{array}{l}\text { Post prognotic } \\
\text { course }\end{array}$ & Baby by ART & Baby by ART & Baby by ART & $\begin{array}{c}\text { Ectopic } \\
\text { pregnancy. By } \\
\text { OUT/Baby by } \\
\text { ART }\end{array}$ & Baby by ART & $\begin{array}{l}\text { Early meno- } \\
\text { pause }\end{array}$ & Baby by ART \\
\hline
\end{tabular}

BTO: Bilateral tubal obstruction, PFA:Perifallopian tubal atresia, ART: Assisted reproductive technology, OUT: Oocyte intrauterine transfer, N.F.: Normal finging, 


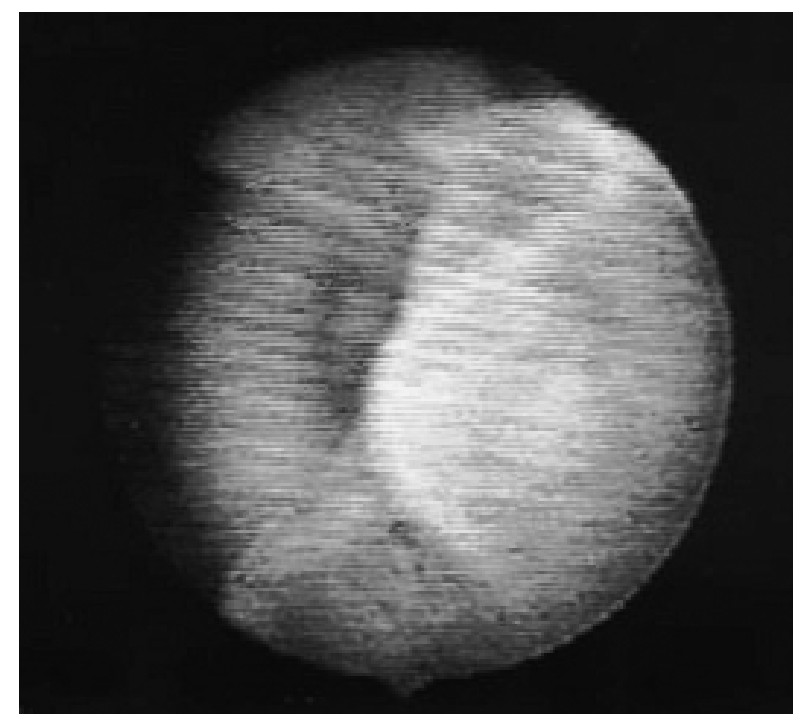

Fig. 1. Lace-like adhesion of perifallopian tube in Case 1.

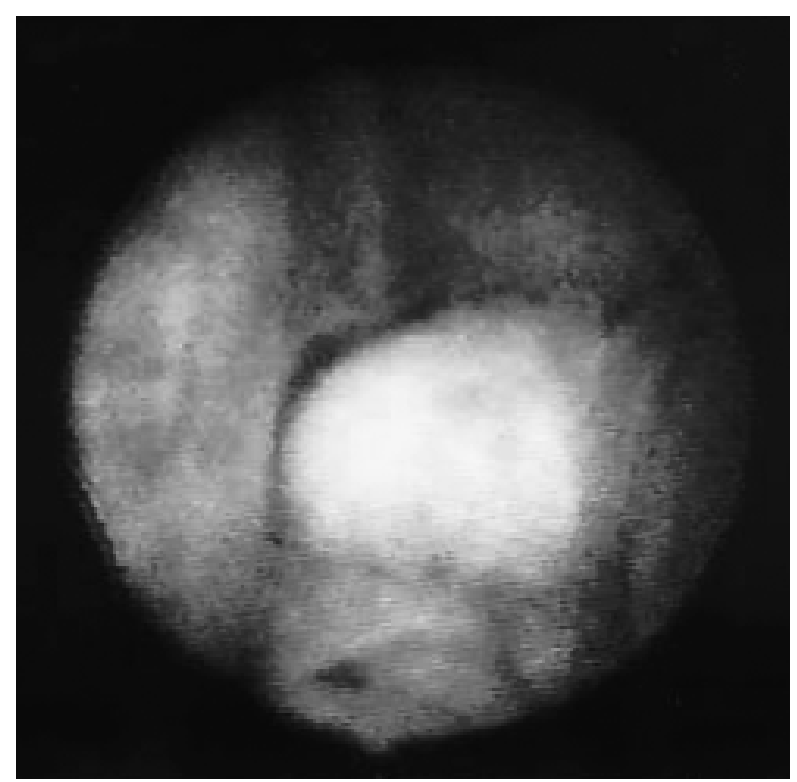

Fig. 3. Peritubal adhesion with sigmoid colon of the left fallopian tube. in Case 4.

to have a baby by assisted reproductive technology (ART) within two years.

\section{DISCUSSION}

In 1998, Gordts et al. [1-3] introduced the concept of transvaginal hydrolaparoscopy to explore the pelvic cavity through a vaginal incision using a saline solution medium. Several reviews have validated the concept of THL in comparison to the gold standard: laparoscopy [10]. In a literature review of 187 patients from

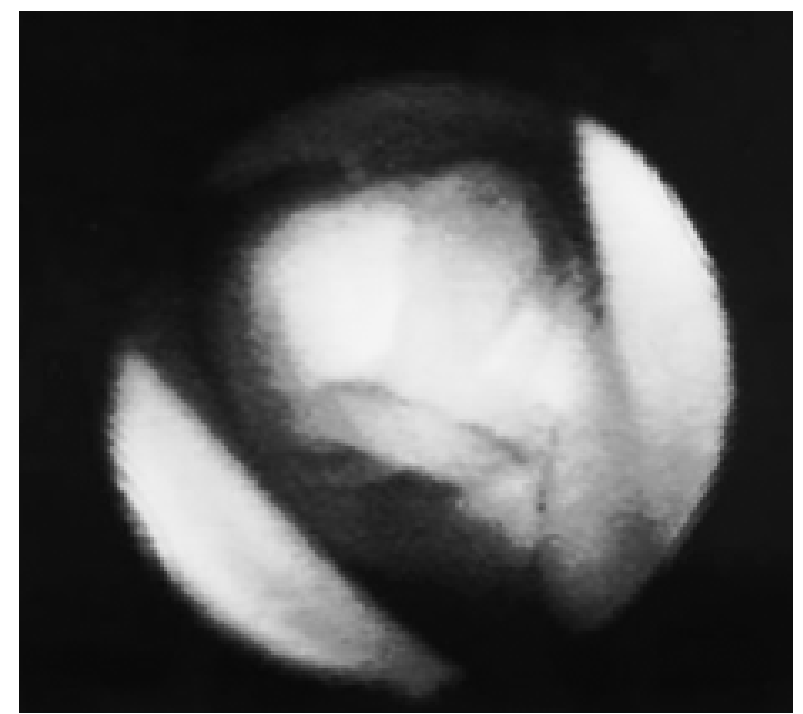

Fig. 2. Floating and distended fimbriae partially adhering the ovary in Case 3.

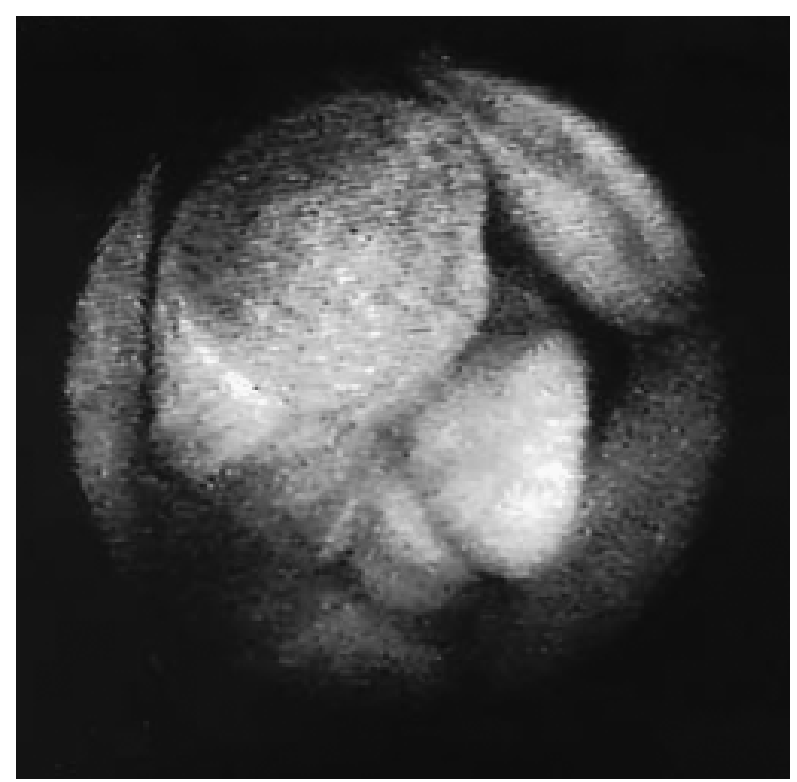

Fig. 4. The balloon-like swelling was observed in the right side fallopian tube in Case 4.

six studies including one prospective double-blind trial, a high concordance was found between THL and laparoscopy ranging from $77.8 \%$ to $100 \%[7,8]$. In a review of 1516 THL, the rate of failure was $5.4 \%$ and these were linked to retroverted uterus and the presence of adhesions [3]. Another review of 1205 THL revealed that complete exploration of the pelvis, including analysis of both sides with visualization of ovaries and tubes, was achieved in $88.3 \%$ of the cases [11-13]. In a review of 4232 procedures from 10 studies, bowel injuries occurred in $0.61 \%$. In a multicenter 
TABLE 2.

Comparisons between THLF and Laparoscopy

\begin{tabular}{lll}
\hline & THLF & \multicolumn{1}{c}{ Laparoscope } \\
\hline (1) Dermatologic incision & No & Multiple smalls \\
(2) Anesthesia & Local & General \\
(3) Invasion & Small & Large for only observation \\
(4) Admission & No & A few days \\
(5) Operative procedures & Difficult & Possible \\
(6) Observation & Clear in fluid & Clear \\
\hline
\end{tabular}

study, the incidence of bowel perforation was $0.65 \%$ and decreased to $0.25 \%$, after an initial learning experience of $50 \mathrm{THL} ; 92 \%$ of these bowel injuries were managed expectantly without consequences [7-9]. In addition to diagnostic THL, the relevance of operative THL has been validated mainly for ovarian drilling for polycystic ovary syndrome. Despite the advantages of THL in terms of cost, reliability as compared to laparoscopy in detecting pelvic abnormalities, and its superiority in detecting subtle lesions, as well as the feasibility of performing it under local anesthesia thereby contributing to the couple's participation, adoption of THL remains relatively low, underlining the need to promote this minimally invasive procedure [1-8].

C. trachomatis is the main agent of PID. The problem is that the majority of cases with $C$. trachomatis infection are asymptomatic and are often referred to as 'silent PID'. Some patients become aware of $C$. trachomatis infection after experiencing infertility or an ectopic pregnancy. The association between $C$. trachomatis antibody in the sera of infertile women and tubal subfertility has been well documented [8-14]. $C$. trachomatis antibody can be determined at low cost and presents no burden to the patient. The discriminative capacity of $C$. trachomatis antibody in the diagnosis of various tubal pathologies was analyzed and it was found to be comparable to that of HSG in the diagnosis of tubal occlusion. It was also suggested that C. trachomatis antibody testing does not seem to be useful in predicting the prognosis of fertility, as it provides no information on the severity of tubal disease.

In current practice, HSG is widely used to assess tubal patency and uterine anomalies [2]. HSG has been a routine examination in many infertility centers as it is less costly and less invasive than laparoscopy. However, laparoscopy is superior in detecting peritoneal adhesions and endometriosis as compared with HSG $[2,7,8]$. In the present study, THLF was used for evaluating tubo-ovarian pathology in infertile women.
THLF is less traumatic than standard laparoscopy. Transvaginal access and the systemic use of hydro floatation are potential advantages of THLF for the exploration of tubo-ovarian structures in infertility $[3,7,8]$. The advantages of THLF include accurate and atraumatic inspection of adnexal structures without manipulation, with the opportunity to perform dye hydrotubation and salpingoscopy. Furthermore, THLF was performed in three cases with retroverted uterus and peritoneal surgical history in spite of contraindication for solid scope THL. THLF was very useful in extending the indications for THL. The risks of a general anesthetic are avoided, and there is less chance of trauma to major vessels (Table 2). There was no complication by THLF in the presented cases.

Six of the 7 patients became pregnant by ART, and discrepancies between HSG and THLF were observed in 3 of the 6 patients. The HSG revealed normal findings in 2 of the 3 women, whereas THLF showed the presence of severe fimbrial adhesions; therefore ART was recommended. Three cases with abnormal findings of both HSG and THLF were also recommended for treatment by ART. Findings on THLF were given precedence in deciding further treatment strategies. We believe that THLF is useful helping these types of patients to successfully achieve early pregnancy. This study is the first trial of THLF.

\section{REFERENCES}

1. Gordts S, Campo R, Rombauts L, and Brosens I. Transvaginal salpingoscopy: and office procedure for infertility investigation. Fertility and Sterility 1998; 70:523526.

2. Gordts S, Campo R, Rombauts L, and Brosens I. Transvaginal hydrolaparoscopy as an outpatient procedure for infertility investigation. 1998; 13:99-103.

3. Gordts S, Campo R, Rombauts K, and Brosens I. Endoscopic visualization of the process of fimbrial ovum retrieval in the human. Human Reprod 1998; 13:1425-1428. 
4. Darai E, Dessolle L, Lecuru F, and Soriano D. Transvaginal hydrolaparoscopy for the evaluation of infertile women: a prospective comparative blind study. Human Reprod 2000; 15:2379-2382.

5. Casa A, Sesti F, Marziali M, and Piccione E. Transvaginal hydrolaparoscopy vs. conventional laparoscopy for evaluationg unexplained primary infertility in women. J Reprod Med 2002; 47:617-620.

6. Akinko-Hakamma KM, Huhtala $\mathrm{H}$, and Tinkanen $\mathrm{H}$. Confirmation of tubal patency in hysterosalpingo-contrast sonography by transvaginal hydrolaparoscopy. Acta Obstet Gynecol Scand 2009; 26:1-5.

7. Darai E, Countant C, Dessolle L, and Ballester M. Transvaginal hydrolaparoscopy. Minerva Chir 2009; 64:365-72.

8. Catenacci M, and Goldberg JM. Transvaginal hydrolaparoscopy. Seminars Reprod Med 2011; 29:95-100.

9. Shibahara H, Shimada K, Kikuchi K, Hirano Y, Suzuki T et al. Major complications and outcome of diagnositic and operative transvaginal hydrolaparoscopy. J Obstet Gynecol Res 2007; 33:705-709.
10. Swart P, Beurden M, Mol BWJ, Redekop WK, van der Veen $\mathrm{F}$ et al. The accuracy of hysterosalphingography in the diagnosis of tubal pathology:a meta-analysis Fertility and Sterility $1995 ; 64: 486-491$.

11. Fernandez H, Alby J-D, Gervaise A, Tayrac R, and Frydman R. Operative transvaginal hydrolaparoscopy for treatment of polycystic ovary syndrome: a new minimally invasive suregery. Fertility and Sterility 2001; 75:607-611.

12. Casa A, sesti F, Marziali M, Gulemi L, and Piccione E. Transvaginal hydrolaparoscopic ovarian drilling using bipolar electrosurgery to treat anovulatory women with polycystic ovary syndrome. J Am Assoc Gynecol Laparosc 2003; 10:219-222.

13. Fujiwara H, Shibahara H, Hirano Y, Suzuki T, Takamizawa $\mathrm{S}$ et al. Usefulness and prognositic value of transvaginal hydrolaparoscopy in infetile women. Fertility and Sterility 2003; 79:186-189.

14. Shibahara H, Fujiwara H, Hirano Y, Suzuki T, Obara H et al. Usefulness of transvaginal hydrolaparoscopy in investigating infertile wome with Chlamydia trachomatis. Human Reprod 2001; 8:1690-1693. 